\title{
CARACTERIZAÇÃO DO ALUNO TRABALHADOR DE CURSOS NOTURNOS DE ENGENHARIA DE UMA UNIVERSIDADE CONFESSIONAL
}

DOI: 10.37702/2175-957X.COBENGE.2021.3373

Giulia Frade Martins - martinsgiulia2507@gmail.com

Mackenzie

Rua Treze de Maio 1601

01327-001 - São Paulo - SP

Raquel Cymrot - rcymrot@gmail.com

Mackenzie

Rua Martinico Prado 242

01224-010 - São Paulo - SP

Resumo: A crise econômica na qual o país se encontra desde a última década fez com que muitos estudantes ingressassem no ensino superior no período noturno para poder trabalhar durante o dia e contribuir com a renda familiar, o que muitas vezes faz com que a vida acadêmica do aluno seja parcialmente comprometida por conta de desta dupla jornada. Entretanto, a necessidade de ajudar em casa não foi única razão para que o aluno ingressasse no mercado de trabalho de forma precoce. $O$ objetivo desta pesquisa foi identificar o perfil do aluno trabalhador de um curso de Engenharia noturno. A pesquisa foi realizada por meio de três questionários aplicados a cada um dos grupos: aluno que que nunca trabalhou durante o curso, aluno que já trabalhou durante o curso, mas não trabalha mais e aluno trabalhador, visando caracterizar o aluno trabalhador e identificar suas diferenças em relação aos demais alunos do período noturno. A amostra constituiu-se de 208 alunos matriculados em uma universidade confessional no curso de Engenharia no período noturno no ano de 2020. Foram realizadas análises descritivas e inferenciais nos dados obtidos. Entre as conclusões, destacou-se que os alunos trabalhadores do período noturno estão trabalhando, em média, mais horas do que determinado pela lei que regula os estágios e pouco mais da metade continuou a ter a faculdade como objetivo principal após ingressar no mercado de trabalho. Foi identificada piora na saúde física, saúde mental, alimentação e sono após o aluno começar a trabalhar. 


\section{(C. COBENGE e IV Simpósio Internacional de Educação em Engenharia

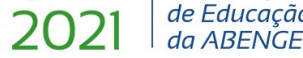 28 a 30 de SETEMBRO

Palavras-chave: Universitários. Aluno trabalhador. Período noturno. 


\section{CARACTERIZAÇÃO DO ALUNO TRABALHADOR DE CURSOS NOTURNOS DE ENGENHARIA DE UMA UNIVERSIDADE CONFESSIONAL}

\section{INTRODUÇÃO}

O Brasil iniciou seu processo de industrialização efetiva a partir da segunda metade do século $X X$, após a Segunda Guerra Mundial. A política de apoio à indústria nacional propiciou a transição para um país industrial e urbano (CANO, 2015).

Tal mudança na economia fez com que grande parte da população rural, que era em sua maioria não escolarizada, migrasse para áreas urbanas em busca de melhores condições de vida. A indústria, por sua vez, foi exigindo do trabalhador uma escolaridade cada vez maior. A partir da década de 1970 houve pressão por abertura de cursos superiores noturnos que propiciassem o estudo para o trabalhador. Por causa da competição existente no ensino superior público, a maioria da população estudantil busca matrícula em instituições privadas de ensino superior. Porém muitos não conseguem permanecer no ensino superior, sendo altas as taxas de evasão. A falta de recursos financeiros ou não conseguir conciliar estudo e trabalho muitas vezes leva o indivíduo, por questões de sobrevivência, a optar pelo trabalho. Problemas financeiros e desempenho deficiente eram indicados, no início do século XXI, como sendo as razões para a alta taxa de desistência do curso (UNGLAUB, 2003).

A $8^{a}$ edição do Mapa do Ensino Superior, pesquisa realizada pelo Sindicato das Entidades Mantenedoras de Estabelecimentos de Ensino Superior no Estado de São Paulo (SEMESP) e divulgada em 2018 apontou que o problema da evasão no ensino superior ainda persiste. As taxas de evasão para o ensino presencial apontadas nesta pesquisa foram: $30,1 \%$ nas instituições privadas e 18,5\% na rede pública (BOCCHINI, 2018).

Segundo Costa (2014) a execução de políticas públicas são um meio de dar oportunidade a jovens de baixa renda para continuar seus estudos e serem assim, mais bem colocados no mercado de trabalho. Com o início do programa do Fundo de Financiamento Estudantil (Fies) em 2001 e com a institucionalização do Programa Universidade para Todos (Prouni) em 2005, estudantes provenientes de classes sociais mais baixas tiveram um acesso facilitado ao curso superior, uma vez que o Prouni oferece bolsas de estudo para alunos com renda familiar per capita de até três salários mínimos e o Fies oferece financiamento para cursos não gratuitos de graduação na educação superior com juros abaixo do mercado (BRASIL, 2015; BRASIL, [2019?]). Em 2019 foram ofertadas 225.555 bolsas pelo Prouni (BRASIL, 2020a).

A partir da implantação do Fies e do Prouni, muitos estudantes provenientes de classes sociais com menor renda puderam ter acesso ao ensino superior privado. Tais estudantes muitas vezes precisam exercer alguma atividade remunerada a fim de custear despesas atreladas à vida acadêmica como compra de livros, necessidade de acesso à internet em casa, transporte, alimentação, entre outros. Entretanto tais alunos não podem negligenciar seus estudos, uma vez que para manutenção dos alunos nos programas citados é necessário que estes tenham um bom desempenho acadêmico.

Segundo Terribili Filho e Barreiro (2013), o ensino superior noturno permite ao aluno trabalhar enquanto cursa sua graduação, podendo custear seus estudos total ou parcialmente, custear suas despesas familiares e até mesmo auxiliar sua família. Entretanto as condições como qualidade do transporte público, presença de congestionamentos nos grandes centros urbanos, falta de segurança pública, dificuldades na flexibilização do horário de trabalho, entre outras, tornam a vida do aluno trabalhador bastante árdua.

Segundo Pereira et al. (2016), o aluno trabalhador, devido à suas atribuições laborais e horas em sala de aula, têm pouco tempo disponível para estudos extraclasse, 
alimentação descanso e sono. Esta circunstância muitas vezes leva a um fraco desempenho acadêmico, dificuldades nas atividades do trabalho, podendo até mesmo gerar problemas de ordem física e emocional.

Segundo Solomon (2016, p. 6), o comportamento do consumidor "[ ...] é o estudo dos processos envolvidos quando indivíduos ou grupos selecionam, compram, usam ou descartam produtos, serviços, ideias ou experiências para satisfazerem necessidades e desejos.".

Pode-se considerar que o aluno é cliente das Instituição de Ensino, pois compra e consome um serviço. Tal papel é mais bem visto do ponto de vista do administrativo da Instituição de Ensino. Entretanto o aluno pode ser entendido como produto da Instituição de Ensino, uma vez a atuação deste aluno, em formação ou formado, em empresas ou na sociedade é um produto disponibilizado graças à atuação da Instituição de Ensino (COSTA, 2007).

O Censo da Educação Superior de 2019 apontou que $67 \%$ das matrículas dos cursos de graduação privados presenciais são do período noturno, resultando em aproximadamente 2.835.818 alunos frequentando cursos noturnos em instituições privadas no ano de 2019 (BRASIL, 2020b).

$\mathrm{Na}$ presente pesquisa foi considerado aluno trabalhador aquele aluno que está inserido no mercado de trabalho formal ou informal, seja efetivado ou estagiando.

A identificação do perfil dos alunos trabalhadores de cursos noturnos de Engenharia pode auxiliar a instituição de ensino a proporcionar uma forma de melhor conciliar as atividades laborais e acadêmicas. Pode também identificar se há necessidade de melhor difundir as atividades que podem ser remuneradas em forma de bolsas dentro da universidade, como realização de monitoria, iniciação científica, participação em esportes representando a universidade, entre outras.

O setor de educação superior apresenta grande competitividade, sendo importante para a satisfação do seu corpo discente e para a minimização das evasões conhecer o perfil de seus alunos, especialmente os que, por serem alunos trabalhadores, possuem uma situação mais crítica. Levando-se em conta a dupla jornada do aluno trabalhador e a complexidade de um curso de Engenharia, que necessita de estudos diários, é possível questionar: Qual o perfil do aluno trabalhador do período noturno de Engenharia?

O objetivo geral desta pesquisa foi identificar o perfil do aluno trabalhador dos cursos de Engenharia noturno de uma universidade confessional. Os objetivos específicos foram: estimar o número médio de horas diárias que o aluno trabalhador do período noturno dos cursos de Engenharia gasta nos deslocamentos para ir e vir do trabalho e na atividade laboral exercida e estimar a etapa média em que se inseriram no mercado de trabalho; estimar a proporção de alunos do período noturno dos cursos de Engenharia que estão inseridos no mercado de trabalho, que são efetivados, que já na época do vestibular pretendiam se tornar alunos trabalhadores, que já pensaram em abandonar o curso; identificar as percepções dos alunos trabalhadores do período noturno dos cursos de Engenharia quanto à influência positiva e negativa que o trabalho traz para seu desempenho acadêmico, identificar suas principais queixas com respeito a sua saúde e qualidade de vida e verificar as principais diferenças de perfil ao comparar os alunos que trabalham com os que nunca trabalharam e com os que já trabalharam mas não trabalham mais.

\section{METODOLOGIA}

A instituição na qual foi realizada a pesquisa tem cursos de Engenharia no período integral e noturno. Os cursos integrais têm apenas as seis primeiras etapas (três anos) no período diurno. A partir da sétima etapa (quarto ano) os cursos de Engenharia passam a ser todos noturnos. 
O questionário elaborado foi baseado no referencial teórico tendo sido aplicado, devido à pandemia do Covid 19 por meio da internet, sendo realizada no mês de junho de 2020. A pesquisa foi submetida e aprovada no Comitê de Ética para Pesquisa da Instituição.

Três questionários distintos foram aplicados aos alunos matriculados no período noturno, dependendo de eles pertencerem a cada uma destas três categorias: serem alunos trabalhadores, já terem sido alunos trabalhadores, mas atualmente não mais trabalharem e nunca terem sido alunos trabalhadores.

Foi elaborado um documento convidando os alunos a participarem da pesquisa, informando sobre sua realização, seus objetivos e os links de acesso aos três questionários. Tal documento foi disponibilizado eletronicamente para os representantes de todas as turmas do período noturno dos cursos de Engenharia, sendo solicitado que estes repassassem o documento para todos os alunos da turma. Os links conduziam a questionários no Google Forms. Os três tipos de questionário se iniciavam com o Termo de Consentimento Livre e Esclarecido para participantes da pesquisa, conforme determinação do Comitê de Ética para Pesquisas. Somente após se assinalar o acordo em participar da pesquisa, o questionário ficava disponível para ser respondido. Como as respostas obtidas no questionário preenchido no Google Forms já vêm tabuladas, sem identificação de origem e como os três tipos de questionário não identificavam o respondente, preservou-se o anonimato dos participantes da pesquisa.

Após a consolidação do banco de dados, foi realizada uma análise descritiva dos dados com cálculo de distribuição de frequências, média, medidas de tendência centrais e de variabilidade, bem como a construção de gráficos.

Foram usados testes $t$ de Student para médias e para comparação de médias para dados pareados na comparação do número de horas de estudo e da percepção do aluno para suas condições de saúde antes de trabalhar e no momento atual em que trabalha (MONTGOMERY; RUNGER. 2018)

Para testar se a média foi igual para dados de amostras correspondentes (avaliação de diversas condições de saúde por um mesmo pesquisado) foi utilizado o teste não paramétrico de Friedman (SIEGEL; CASTELLAN, 2008).

Devido ao pequeno tamanho dos grupos de alunos que nunca trabalharam e de alunos que já trabalharam, porém não estavam mais trabalhando, para comparar as médias nos três grupos foi realizada uma análise de variância não paramétrica por meio do teste de Kruskal-Wallis (SIEGEL; CASTELLAN, 2008).

Para comparar médias de variáveis entre os grupos de alunos trabalhadores e de alunos que já trabalharam, porém não estavam mais trabalhando, devido ao pequeno tamanho deste último grupo foi realizado o teste não paramétrico de Mann-Whitney (SIEGEL; CASTELLAN, 2008).

Foram realizados testes de independência para pares de variáveis por meio do teste Qui-Quadrado, observando-se se as suposições para aplicação de tal teste estavam satisfeitas. Quando não estavam, níveis de uma das variáveis foram agrupados de modo a satisfazer tais suposições. Quando mesmo com apenas dois níveis em cada variável as suposições não estavam respeitadas foi usado o teste de independência exato de Fisher (SIEGEL; CASTELLAN, 2008).

Todos os intervalos de confiança (I.C.) foram calculados adotando-se uma confiança igual a $95 \%$ e para todos os testes de hipótese foram adotados níveis de significância de $5 \%$, sendo assim rejeitadas as hipóteses com níveis descritivos (valores-p) inferiores a 0,05.

As análises estatísticas foram realizadas utilizando-se os programas Microsoft Excel $®$ e Minitab $®$ Statistical Software v. 19. 
A pesquisa for realizada no mês de junho de 2020, os pesquisados foram alunos da $1^{\mathrm{a}}$ à $10^{\mathrm{a}}$ etapa dos cursos de Engenharia do período noturno. A amostragem foi por acessibilidade, pois recebendo os links que conduziam aos questionários, cabia ao aluno decidir se iria responder ao questionário do grupo ao qual pertencia. Alunos menores de 18 anos e alunos que cursavam a maior parte das disciplinas no período diurno foram orientados a não responder a pesquisa.

Foi coletada uma amostra de 208 pesquisados na qual $9(4,33 \%)$ eram alunos que já trabalharam e não trabalham mais, $23(11,06 \%)$ alunos que nunca trabalharam e $176(84,62 \%)$ alunos trabalhadores. Dentre os pesquisados, $56,73 \%$ eram do sexo masculino e a idade variou de 18 a 34 anos com média igual a 22,3 anos (I.C. = [22,0; 22,6] anos). O Gráfico 1 apresenta as porcentagens da amostra por faixa de renda domiciliar mensal em salários mínimos (SM).

Gráfico 1 - Renda domiciliar mensal

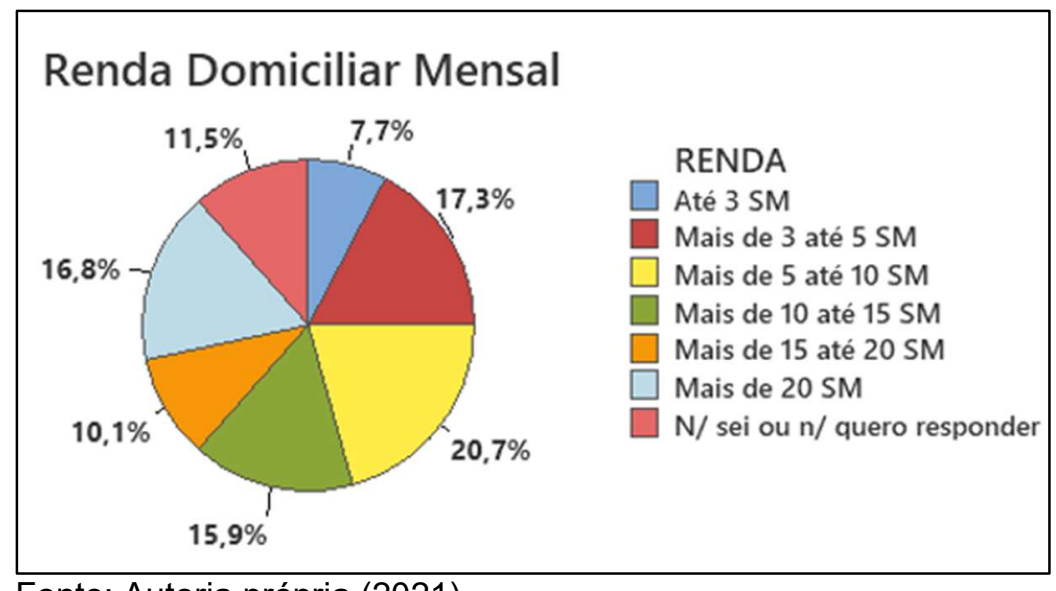

Fonte: Autoria própria (2021)

Tem-se também que $17,79 \%$ (I.C. $=[12,84 ; 23,67] \%$ ) dos respondentes eram beneficiários de programas do Governo Federal de acesso ao ensino superior privado. Entre todos os bolsistas de programas do Governo Federal 2,70\% tinham bolsa parcial PROUNI, $72,97 \%$ bolsa integral PROUNI e $24,32 \%$ bolsa FIES. Dentre os alunos pesquisados, $12,02 \%$ eram beneficiados de programas universitários da UPM, sendo que dentre os bolsistas $4,00 \%$ tinham bolsa do PRAVALER, $4,00 \%$ do Bradesco, $56,00 \%$ bolsa Filantrópica e $36,00 \%$ outras bolsas.

Quanto à moradia, 82,21\% apontaram morar com mãe, pai, tios, avós, 2,88\% só com irmãos, primos, $7,69 \%$ sozinhos, $4,33 \%$ com cônjuge/companheiro(a) e 2,88\% com amigos.

Apenas $78,85 \%$ (I.C. $=[73,30 ; 84,40] \%$ ) dos pesquisados indicaram ter conhecimento sobre bolsas oferecidas, como as de monitoria, de projetos de iniciação científica ou de outros projetos de pesquisa e extensão da UPM e 18,27\% (I.C. = [13,27; $24,20] \%)$ já tiveram esta modalidade de bolsa. Também 91,35\% (I.C. = [87,52; 95,17] \%) dos respondentes apontaram ter conhecimento sobre a Empresa Júnior, sendo que 7,21\% (I.C. $=[4,09 ; 11,62] \%)$ pertencem ou já pertenceram a seus quadros.

Os pesquisados apontaram que na época do vestibular, $8,65 \%$ não pretendiam se tornar um aluno trabalhador antes da sétima etapa, que é a etapa na qual o curso integral passa a ser noturno, visando facilitar a entrada dos alunos no mercado de trabalho. Obtevese que $55,77 \%$ dos pesquisados pretendiam trabalhar antes da sétima etapa, 22,59\% não tinham pensado no assunto e $12,98 \%$ já trabalhavam antes de ingressar no curso. 
Quanto ao número semanal médio de horas que o aluno dedicava aos estudos fora da faculdade quando não trabalhava e não estava em época de provas, a média encontrada foi de $16,51 \mathrm{~h}(\mathrm{I} . \mathrm{C}=[13,98 ; 19,05] \mathrm{h})$. Já em época de provas a média foi de $28,00 \mathrm{~h}(\mathrm{I} . \mathrm{C}=[24,43 ; 31,57] \mathrm{h})$.

Ao serem perguntados o quão frequente pensavam em desistir do curso de Engenharia, quando não trabalhavam, 48,02\% responderam que nunca, $22,03 \%$ poucas vezes, $19,21 \%$ às vezes, $8,47 \%$ muitas vezes e $2,26 \%$ sempre.

Sobre qualidade de vida quando não trabalhavam, a autoavaliação da saúde física foi $2,87 \%$ péssima, $7,47 \%$ ruim, $20,69 \%$ regular, $45,40 \%$ boa e $23,56 \%$ excelente. A autoavaliação da saúde mental foi $4,00 \%$ péssima, $9,14 \%$ ruim, $23,43 \%$ regular, $40,00 \%$ boa e $23,43 \%$ excelente. Já a alimentação foi autoavaliada 1,71\% como péssima, 8,00\% como ruim, 29,71\% como regular, $43,43 \%$ como boa e $17,14 \%$ como excelente. Por último, a autoavaliação quanto ao sono foi $3,49 \%$ péssima, $6,40 \%$ ruim, $19,77 \%$ regular, $32,56 \%$ boa e $37,79 \%$ excelente.

\subsection{Análise do questionário para o aluno trabalhador}

Na presente pesquisa foi coletada uma amostra de 176 alunos trabalhadores, na qual $3,41 \%$ exerciam atividade informal, $60,80 \%$ estavam estagiando e 35,80\% já eram efetivos.

Quanto à etapa na qual começaram a trabalhar, $17,0 \%$ dos alunos já começaram o curso trabalhando, $28,5 \%$ ingressaram no mercado entre a primeira e terceira etapa e $38,1 \%$ entre a quarta e sexta etapa, portanto $86,3 \%$ dos respondentes ingressaram no mercado de trabalho antes da sétima etapa, etapa na qual o curso integral passa a ser noturno, visando facilitar a entrada dos alunos no mercado de trabalho.

Teve-se que $55,11 \%$ (I.C. $=[47,77 ; 62,46] \%$ ) dos alunos trabalhadores indicaram que depois de ingressar no mercado de trabalho, seu objetivo principal continuou sendo o curso.

Os alunos trabalhadores indicaram gastar em média $7,8 \mathrm{~h}$ (I.C. $=[7,5 ; 8,07] \mathrm{h}) \mathrm{no}$ trabalho e $2,1 \mathrm{~h}(\mathrm{I} . \mathrm{C} .=[1,91 ; 2,23] \mathrm{h})$ no deslocamento até o trabalho. A porcentagem de alunos que passavam mais de 6 horas no trabalho foi igual a 72,16\% (I.C. $=[64,92 ; 78,64] \%)$.

Os alunos que estagiavam estavam trabalhando em média $7,02 \mathrm{~h}$ (I.C. $=[6,74 ; 7,30]$ \%) por dia, os efetivos $8,8 \mathrm{~h}$ (I.C. $=[8,47 ; 9,16] \mathrm{h}$ ) e os informais $10,7 \mathrm{~h}$ (I.C. $=[6,08 ; 15,25]$ h) não havendo para efetivos e informais regulação para carga horária máxima de trabalho. Entretanto a lei exige que estagiários não trabalhem mais que 6h por dia com a intenção de diminuir o prejuízo da dupla jornada para a vida acadêmica do aluno. O Gráfico 2 apresenta o número médio de horas por dia o trabalho.

Quando questionados se na época do vestibular, pretendiam se tornar um aluno trabalhador antes da sétima etapa, 9,09\% indicaram que não, 51,70\% indicaram que sim, $23,86 \%$ disseram que não pensavam neste assunto e 15,34 já trabalhavam antes de ingressar no curso.

A hipótese de que a frequência média com que os alunos trabalhadores pensavam em desistir do curso de Engenharia era no máximo pouco $(\mathrm{HO}: \mu \leq 2)$ não foi rejeitada $(p=0,525)$. Os motivos de ingressar no mercado de trabalho precocemente foram: 69,88\% por independência, 80,68\% para adquirir experiência para o currículo, 50,57\% para ajudar na renda familiar, $26,70 \%$ para se manter no curso, $24,43 \%$ a ascensão social, $11,36 \%$ por pressão social e 3,97\% alegaram outros motivos. Ressalta-se de que era permitido marcar mais de um motivo.

Ao avaliar o quanto o seu rendimento acadêmico era prejudicado por causa da dupla jornada, a resposta foi 3,41\%, 8,52\%, 42,05\%, 37,50\% e 8,52\% respectivamente para nada, pouco, moderadamente, muito e totalmente. Já a avaliação da influência positiva do trabalho o seu desempenho acadêmico foi 10,23\%, 26,70\%,35,23\%, 23,30\% e 4,55\% respectivamente para nada, pouco, moderadamente, muito e totalmente. 
Gráfico 2 - número de horas médias diárias no trabalho

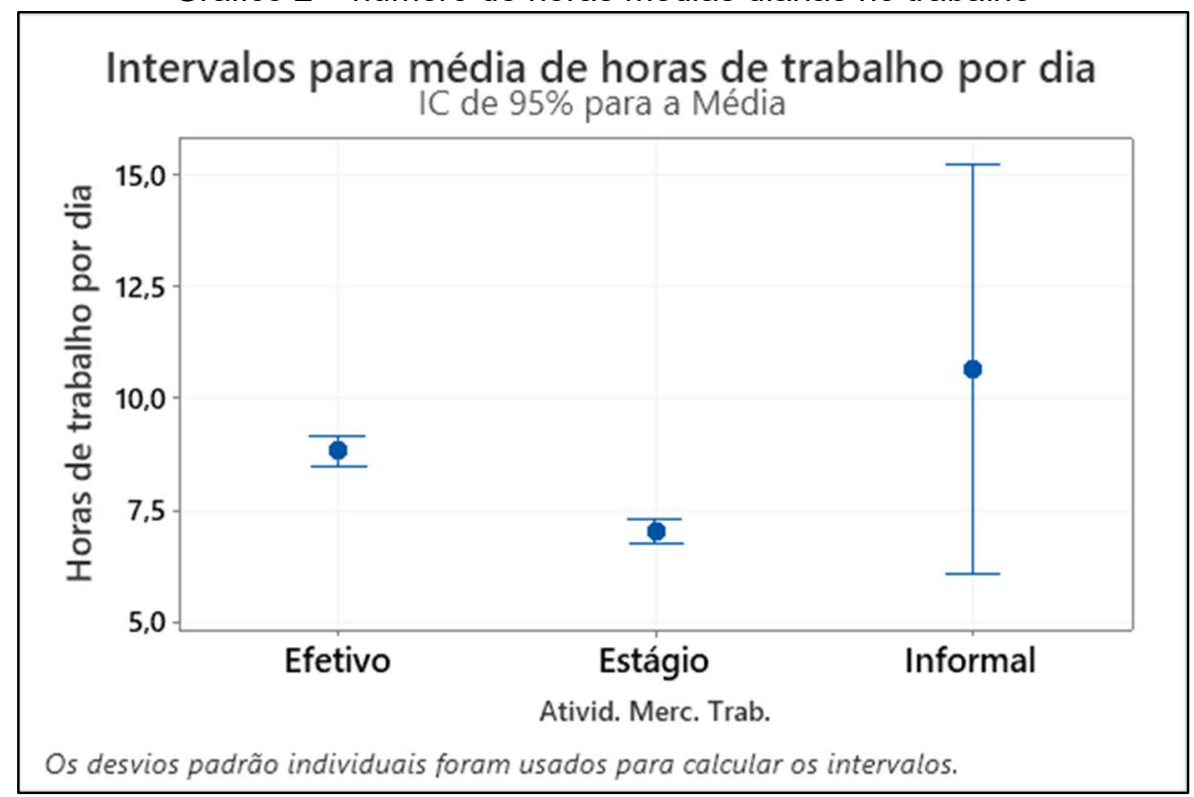

Fonte: Autoria própria (2021)

Ao se atribuir uma escala de 1 a 5 correspondentes as respostas "nada" até "totalmente", o prejuízo médio no rendimento acadêmico por causa da dupla jornada foi igual a 3,39 (I.C. = $[3,26 ; 3,52])$ considerado superior a 2 , que corresponde a ser superior a pouco $(p=0,000)$. Por sua vez a influência média positiva no desempenho acadêmico devido a atividade laboral foi igual a 2,85 (I.C. $=[2,70 ; 3,01])$ considerado superior a 2 , que corresponde a ser superior a pouco $(p=0,000)$. Conclui-se então que o rendimento acadêmico foi influenciado tanto positivamente quanto negativamente pela situação do aluno ser trabalhador.

Ao assinalar as influências positivas que o trabalho trazia para seu desempenho acadêmico, $80,11 \%$ indicaram que possibilitava conhecer diversas áreas de atuação da profissão, descobrir interesses, orientar escolhas dentro do curso e de projeto profissional, $76,70 \%$ indicaram o aprimoramento de suas habilidades que dizem respeito às relações pessoais, $46,60 \%$ que fazia o paralelo entre o conhecimento do que se aprende na faculdade com o conhecimento da prática, o que melhora seu desempenho acadêmico e $1,70 \%$ haver outras influências positivas.

Quanto às influências negativas que o trabalho trazia para seu desempenho acadêmico, 93,75\% indicaram que devido à dupla jornada, tinham dificuldades em gerenciar seu tempo para os estudos, causando a diminuição do desempenho acadêmico, $86,36 \%$ que tinham dificuldades em manter-se interessados nas aulas por causa do cansaço devido à dupla jornada, $35,23 \%$ passaram a ter mais faltas na faculdade, $45,45 \%$ passaram a chegar mais atrasado nas aulas e 5,68\% indicaram haver outras influências negativas.

A pesquisa indicou a porcentagem dos alunos trabalhadores que ao chegar ao trabalho se sentiam: $66,48 \%$ (I.C. $=[59,50 ; 73,45] \%$ ) cansados, 46,59\% (I.C. $=[39,22$; $53,96] \%)$ felizes, $37,50 \%$ (I.C. $=[30,35 ; 44,65] \%)$ com problemas de sono, $19,32 \%($ I.C. $=$ $[13,49 ; 25,15] \%)$ tensos e agitados e $17,04 \%$ (I.C. = $[11,49 ; 22,60] \%)$ com dores de cabeça. Tem-se também que a porcentagem dos alunos trabalhadores que ao chegar na universidade se sentiam foi: $84,66 \%$ (I.C. $=[79,33 ; 89,98] \%)$ cansados, $21,02 \%$ (I.C. $=$ $[15,00 ; 27,04] \%)$ felizes, $39,20 \%$ (I.C. $=[31,95 ; 46,83] \%)$ com problemas de sono, $48,30 \%$ (I.C. $=[40,91 ; 55,68] \%)$ desinteressados, 21,59\% (I.C. $=[15,51 ; 27,67] \%)$ tensos e agitados e $27,84 \%$ (I.C. $=[21,22 ; 34,46] \%)$ com dores de cabeça.

Sobre qualidade de vida hoje, a autoavaliação da saúde física foi: 9,09\% péssima, $27,84 \%$ ruim, $43,18 \%$ regular, $18,75 \%$ boa e $1,14 \%$ ótima. A autoavaliação da saúde mental 
foi $9,66 \%$ péssima, $18,18 \%$ ruim, $31,82 \%$ regular, $36,36 \%$ boa e 3,98\% ótima. Já a alimentação foi autoavaliada $5,11 \%$ como péssima, $28,41 \%$ como ruim, $37,50 \%$ como regular $23,86 \%$ como boa e $5,11 \%$ como ótima. Por último, a autoavaliação quanto ao sono foi $26,71 \%$ péssima, $43,75 \%$ ruim, $21,59 \%$ regular, $6,82 \%$ boa e $1,14 \%$ ótima. Em contrapartida quando não trabalhavam, a autoavaliação da saúde física foi: $2,11 \%$ péssima, $5,63 \%$ ruim, $19,72 \%$ regular, $44,37 \%$ boa e $28,17 \%$ ótima. A autoavaliação da saúde mental foi $3,50 \%$ péssima, $8,39 \%$ ruim, $19,58 \%$ regular, $41,96 \%$ boa e $26,57 \%$ ótima. Já a alimentação foi autoavaliada $1,40 \%$ como péssima, $7,69 \%$ como ruim, $29,37 \%$ como regular, $40,56 \%$ como boa e $20,98 \%$ como ótima. Por último, a autoavaliação quanto ao sono foi $1,43 \%$ péssima, $5,00 \%$ ruim, $16,43 \%$ regular, $33,57 \%$ boa e $43,57 \%$ ótima.

Atribuindo-se postos de 1 a 5 para as classificações respectivamente péssimo, ruim, regular, bom e ótimo, tem-se que média obtida foi igual, para a avaliação do presente, de 2,75 para saúde física, 3,07 para saúde mental, 2,95 para alimentação e 2,12 para sono. Ao testar se esta média era no máximo regular $(\leq 3)$, nenhum teste foi rejeitado, indicando que a avaliação não foi positiva (acima de regular) para nenhuma variável avaliada, sendo os valores-p respectivamente iguais a 1,000, 0,194, 0,733 e 1,000 para saúde física, saúde mental, alimentação e sono.

Para os alunos trabalhadores, utilizando-se os postos atribuídos, foi feita a diferença entre as médias obtidas antes e depois do aluno começar a trabalhar com relação à saúde física, saúde mental, alimentação e sono, sendo a hipótese de que não houve piora após a entrada no mercado de trabalho rejeitada para todas as variáveis com todos os valores-p iguais a 0,000.

Utilizando-se uma escala de 1 a 5 para as classificações das avaliações, o teste de Friedman apontou que houve diferença nas avaliações das variáveis quando o aluno não trabalhava, sendo a melhor avaliação dada para o sono e a pior para a alimentação ( $p=$ $0,000)$. Já a avaliação no momento atual no qual trabalhava também revelou que as avaliações diferiram, sendo a mais bem avaliada a saúde mental e o mais mal avaliado o sono. O teste de Friedman confirmou que após começar a trabalhar a menor piora foi na avaliação da saúde mental e a maior piora foi na avaliação do sono $(p=0,000)$. O Gráfico 3 ilustra os resultados obtidos, sabendo-se que valores de 1 a 5 para as classificações correspondem respectivamente às avaliações: péssimo, ruim, regular, bom e ótimo.

Gráfico 3 - Intervalos de confiança para avaliações de condições de saúde antes de trabalhar e quando trabalha

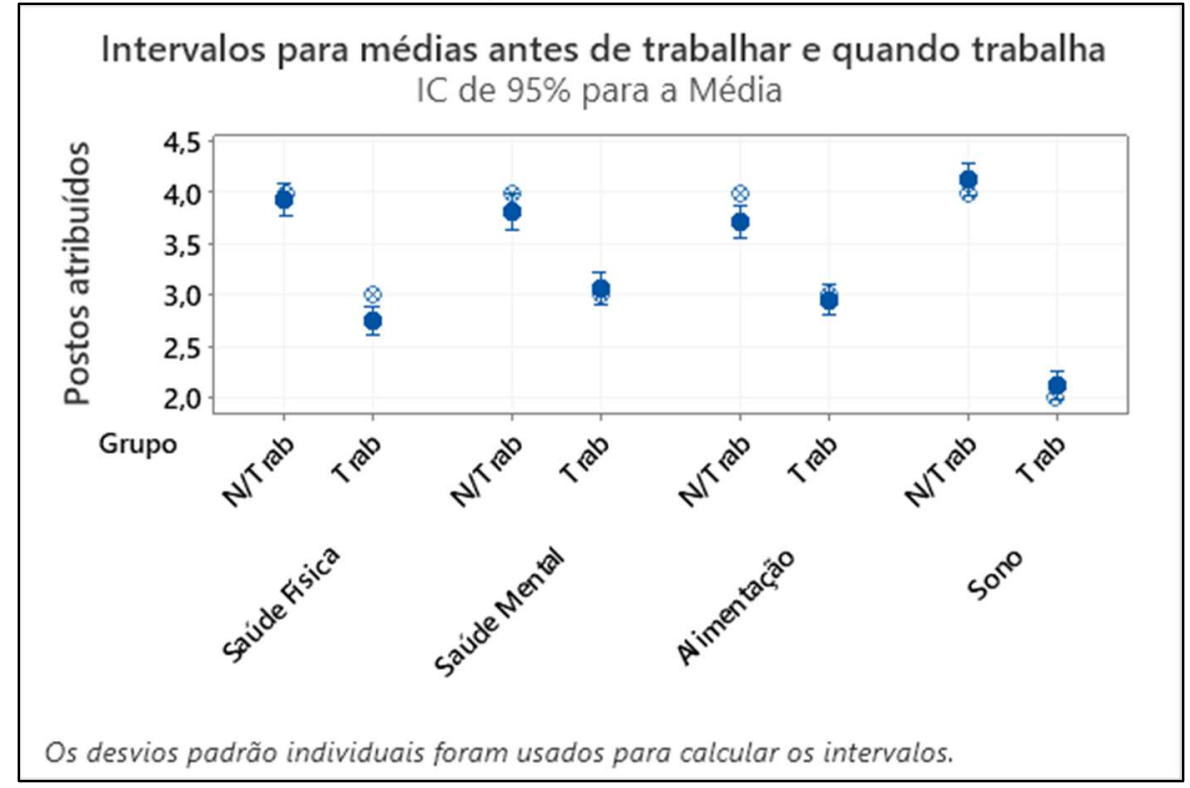

Fonte: autoria própria (2020) 


\subsection{Comparação dos resultados das análises dos três questionários}

Algumas conclusões foram possíveis, considerando-se os grupos alunos trabalhadores, alunos que nunca trabalharam e alunos que já trabalharam, mas não trabalham mais.

As interpretações dos testes Qui-Quadrado de independência resultaram que o aluno trabalhador avaliou proporcionalmente a sua saúde física menos positivamente que os demais $(p=0,000)$, bem como sua alimentação $(p=0,008)$ e seu sono $(p=0,000)$.

Utilizando o Teste de Kruskal-Wallis, foi constatado que entre os pesquisados a idade média diferiu nos três grupos, sendo considerada menor $(p=0,023)$ no grupo de alunos que nunca trabalharam (21,6 anos), quando comparado aos alunos trabalhadores (22,4 anos) e aos que já trabalharam, mas não trabalham mais $(23,7$ anos).

O teste de Kruskal-Wallis indicou não haver diferença de médias para a avaliação da saúde mental hoje nos três grupos $(p=0,403)$, sendo as três consideradas no máximo regular. Na média da avaliação da saúde física se identificou diferença nos três grupos, sendo maior no grupo de alunos que já trabalharam, mas não trabalham mais $(3,44$, entre regular e bom) e menor no grupo de alunos trabalhadores $(2,75$, entre ruim e regular) $(p=$ 0,011). A avaliação média da alimentação também foi diferente nos três grupos com o aluno trabalhador $(2,95$, entre ruim e regular) pior avaliado que o que já trabalhou $(3,67$, entre regular e bom), ficando o aluno que nunca trabalhou entre os dois $(3,30$, entre ruim e regular) podendo indicar que o aluno que não trabalha mais pode ter uma memória ruim em relação à quando trabalhava e fez uma avaliação superestimada do momento atual ( $p$ $=0,018$ ). Com relação ao sono as médias também divergiram, tendo os grupos dos alunos que já trabalharam $(3,67$, entre regular e bom) e dos que nunca trabalharam $(2,96$, entre ruim e regular) avaliado melhor seu sono atual e o grupo dos alunos trabalhadores $(2,11$, ruim e regular) avaliado pior seu sono atual.

Ainda utilizando-se o teste de Kruskal-Wallis concluiu-se que o tempo semanal de estudo em época normal difere nos três grupos, sendo maior no grupo de alunos que nunca trabalharam $(18,6 \mathrm{~h})$ e menor no grupo de alunos trabalhadores $(5,2 \mathrm{~h})(\mathrm{p}=0,000)$. 0 mesmo resultado foi encontrado para época de provas, com em média 30,6 h de estudo semanal para o aluno que nunca trabalhou e $14,1 \mathrm{~h}$ para o aluno trabalhador $(p=0,000)$. Ao avaliar quão frequente o aluno pensava em desistir do curso, em uma escala de 1 a 5 e utilizando-se o teste de Kruskal-Wallis, as frequências médias foram consideradas iguais nos três grupos, estando entre 1,67 e 2,01, o equivalente a poucas vezes $(p=0,812)$.

Pertencer ao grupo ser trabalhador ou não ser trabalhador, mesmo já tendo trabalhado anteriormente, foi independente de ser: beneficiário de programa do governo ( $p$ $=0,461)$, beneficiário de programa universitário $(p=0,235)$, do sexo $(p=0,684)$, de conhecer sobre bolsas oferecidas, como as de monitoria, de projetos de iniciação científica ou de outros projetos de pesquisa e extensão da UPM $(p=0,562)$ e de ter ou ter tido bolsa $(p=0,359)$.

\subsection{Comparação dos resultados das análises dos questionários para alunos trabalhadores e alunos que já foram trabalhadores}

Algumas variáveis não foram abordadas nos três instrumentos de pesquisa por não serem pertinentes em algumas situações. As análises que se seguem foram realizadas baseadas nos questionários dos alunos trabalhadores e dos alunos que já foram alunos trabalhadores, mas atualmente não mais trabalham. 
Houve independência entre pertencer a um dos dois grupos e as variáveis: ser beneficiário de programa do governo $(p=1,000)$, ser beneficiário de programa universitário $(p=0,077)$, sexo $(p=1,000)$, conhecer bolsas oferecidas $(p=0,401)$, ter ou ter tido alguma dessas bolsas $(p=0,688)$, conhecer a EJEM $(p=0,141)$, trabalhar ou ter trabalhado na EJEM $(p=1,000)$, se o objetivo continuou sendo a faculdade $(p=0,303)$.

Pertencer a cada um dos dois grupos também foi independente a ter como motivo para decidir ingressar no mercado de trabalho precocemente (antes da sétima etapa): ajudar na renda familiar ( $p=0,747)$, ascensão social $(p=0,235)$, para adquirir experiência para o currículo $(p=0,688)$, para se manter na faculdade $(p=1,000)$ e por pressão social $(p=0,600)$. Entretanto não houve independência entre grupo e ter como motivo para decidir ingressar no mercado de trabalho precocemente obter independência $(p=0,031)$, sendo que proporcionalmente, quem já trabalhou, mas atualmente não trabalha, teve menos como motivo para decidir ingressar no mercado de trabalho precocemente obter independência.

As avaliações das seguintes influências positivas que o trabalho trouxe para o desempenho acadêmico foram independentes de o aluno ser trabalhador ou já ter sido trabalhador: fazer o paralelo entre o conhecimento do que se aprende na faculdade com o conhecimento da prática, o que melhora o desempenho acadêmico $(p=0,510)$ e aprimoramento das habilidades que dizem respeito às relações pessoais $(p=0,211)$. Entretanto, proporcionalmente o aluno que já trabalhou, mas não trabalha mais apontou menos como influência positiva do que aluno trabalhador que o trabalho trouxe para seu desempenho acadêmico a possibilidade de conhecer diversas áreas de atuação da profissão, descobrir interesses, orientar escolhas dentro do curso e de projeto profissional $(p=0,024)$.

As avaliações das seguintes influências negativas que o trabalho trouxe para o desempenho acadêmico foram independentes de o aluno ser trabalhador ou já ter sido trabalhador: devido a dupla jornada, ter dificuldades em gerenciar seu tempo para os estudos, causando a diminuição do seu desempenho acadêmico $(p=0,461)$, ter dificuldades em manter-se interessado nas aulas por causa do cansaço devido à dupla jornada ( $p=0,687$ ), sentir que houve uma diminuição do seu interesse nas aulas e nos assuntos que dizem respeito à faculdade $(p=1,000)$, passar a ter mais faltas na faculdade $(p=0,721)$, passar a chegar mais atrasado nas aulas $(p=0,307)$.

O grupo a que pertence o aluno foi independente dos seguintes estados ao chegar ao trabalho: estar cansado $(p=0,492)$, estar tenso e agitado ( $p=0,386)$, estar com problemas de sono $(p=0,742)$, estar com dores de cabeça ( $p=1,000)$, estar desinteressado $(p=0,627)$ e estar feliz $(p=0,510)$.

O grupo a que pertence o aluno também foi independente dos seguintes estados ao chegar à universidade: estar cansado $(p=0,634)$, estar tenso e agitado $(p=1,000)$, estar com problemas de sono ( $p=0,741)$, estar com dores de cabeça $(p=1,000)$ e estar desinteressado $(p=0,502)$ e chegar feliz à universidade $(p=0,688)$.

Por meio do teste de Mann-Whitney para diferença de médias concluiu-se que as horas gastas em média no trabalho foram iguais para os dois grupos ( $p=0,337)$, tal como as horas gastas em média no trajeto para o trabalho $(p=0,104)$, horas semanais de estudo sem provas quando não trabalhavam $(p=0,667)$, horas semanais de estudo com provas quando não trabalhavam $(p=0,978)$, horas semanais de estudo sem provas quando trabalhavam $(p=0,085)$, horas semanais de estudo com provas quando trabalhavam $(p=$ 0,282). 


\section{CONSIDERAÇÕES FINAIS}

A partir desta pesquisa foi possível identificar algumas características relevantes com relação ao aluno trabalhador e suas diferenças e semelhanças em relação ao aluno que nunca trabalhou e ao aluno que já trabalhou, mas não trabalha mais.

Perto de um quarto dos alunos pesquisados indicaram não ter conhecimento das bolsas oferecidas pela universidade, tais como as de monitoria, de projetos de iniciação científica ou de outros projetos de pesquisa e extensão, o que sugere que a divulgação destas não está atingindo todo o alunato.

Mais da metade dos alunos do curso noturno assinalaram que ao ingressar na universidade já pretendiam trabalhar antes da sétima etapa, que é quando o curso integral passa a ser noturno, visando facilitar a entrada dos alunos no mercado de trabalho e mais de $80 \%$ dos alunos efetivamente ingressaram no mercado de trabalho antes da sétima etapa. Também se observou que pouco mais de $10 \%$ dos alunos do curso noturno já ingressaram no curso na condição de alunos trabalhadores.

Ressalta-se um resultado alarmante desta pesquisa: quase a metade dos alunos trabalhadores do período noturno não tem o curso como seu principal objetivo.

Quase três quartos dos alunos que trabalhavam atestaram trabalhar mais do que a jornada de 6 horas por dia, que é o número de horas diárias que a lei que trata de estágios coloca como número máximo de horas permitidas de modo a minimizar o prejuízo da dupla jornada para a vida acadêmica do aluno. Na amostra avaliada, alunos com trabalhos informais exerciam a atividade laboral, em média, por mais de 10 horas por dia enquanto os efetivos trabalhavam em média quase 9 horas por dia. Ressalta-se que dentre os alunos do curso noturno que trabalhavam, quase $40 \%$ eram efetivos ou exerciam atividades informais, não estando protegidos pela lei que versa sobre estágios.

Aproximadamente a metade dos alunos trabalhadores ingressaram no mercado de trabalho para ajudar na renda familiar e aproximadamente um quarto dos alunos trabalhadores para se manter no curso, evidenciando a necessidade financeira como motivo para ingresso no mercado de trabalho.

O rendimento acadêmico foi influenciado tanto para mais, quanto para menos, pela situação do aluno ser trabalhador. As vantagens de se tornar trabalhador mais apontadas foram possibilitar conhecer diversas áreas de atuação da profissão e aprimorar as habilidades que dizem respeito às relações pessoais. Em contraponto as desvantagens mais indicadas foram que devido à dupla jornada, tinham dificuldades em gerenciar seu tempo para os estudos, causando a diminuição do desempenho acadêmico e que tinham dificuldades em manter-se interessados nas aulas por causa do cansaço.

A pesquisa também indicou que os alunos trabalhadores, em sua maioria, chegavam cansados, tanto no trabalho quanto na universidade. A saúde física, saúde mental, alimentação e sono apresentaram piora após o aluno começar a trabalhar, com a saúde mental apresentando a menor piora, talvez devido ao trabalho aumentar a autoestima do aluno. Já a maior piora foi na avaliação do sono, possivelmente por conta da dupla jornada.

Com relação à comparação dos alunos trabalhadores com os alunos que já foram trabalhadores constatou-se que proporcionalmente, quem já trabalhou, mas atualmente não trabalha, teve menos como motivo para decidir ingressar no mercado de trabalho precocemente obter independência.

Identificar o perfil do aluno trabalhador dos cursos de Engenharia noturno de uma universidade confessional poderá auxiliar a instituição de ensino a proporcionar uma forma de melhor conciliar as atividades laborais e acadêmicas. 
O tema é relevante e novas pesquisas devem ser feitas devido às mudanças econômicas, sociais e culturais que ocorrem com o passar do tempo, trazendo efeitos na vida do aluno trabalhador.

\section{REFERÊNCIAS}

BOCCHINI, B. Pesquisa mostra evasão de $\mathbf{3 0} \%$ em cursos superiores privados. Agência Brasil. Educação. Brasília, 27 set. 2018. Disponível em:

http://agenciabrasil.ebc.com.br/educacao/noticia/2018-09/pesquisa-mostra-evasao-de-30em-cursos-superiores-privados. Acesso em: 23 mar. 2019.

BRASIL. Ministério da Educação. Dados e Recursos. Brasília, 2020a. Disponível em: http://dadosabertos.mec.gov.br/prouni. Acesso em: 22 mar. 2021.

BRASIL. Ministério da Educação. Fundo de Financiamento Estudantil. O que é o FIES. Brasília, [2019?]. Disponível em: http://sisfiesportal.mec.gov.br/?pagina=fies. Acesso em: 20 mar. 2019.

BRASIL. Ministério da Educação. Instituto Nacional de Estudos e Pesquisas Anísio Teixeira. Censo da Educação Superior 2019: Divulgação dos resultados. Brasília, 2020b. Disponível em:

https://download.inep.gov.br/educacao superior/censo superior/documentos/2020/Aprese ntacao Censo da Educacao Superior 2019.pdf. Acesso em 08 abr. 2021.

BRASIL. Ministério da Educação. Programa Universidade para Todos. Manual de orientação ao bolsista, Brasília, 2015. Disponível em:

http://prouniportal.mec.gov.br/images/pdf/manual bolsista prouni.pdf. Acesso em: 25 mar. 2019.

CANO, W. Crise e industrialização no Brasil entre 1929 e 1954: a reconstrução do Estado Nacional e a política nacional de desenvolvimento. Rev. Econ. Polit. v. 35, n. 3, São Paulo, Jul./Set. 2015. Disponível em: http://www.scielo.br/scielo.php?pid=S010131572015000300444\&script=sci arttext. Acesso em: 19 mar. 2019.

COSTA, F. J. A influência do valor percebido pelo cliente sobre os comportamentos de reclamação e boca a boca: uma investigação em cursos de pós-graduação latu sensu. Tese (doutorado em Administração de Empresas) - Escola de Administração de Empresas de São Paulo, Fundação Getúlio Vargas, São Paulo, 2007. Disponível em: http://bibliotecadigital.fgv.br/dspace/bitstream/handle/10438/2518/166815.pdf?sequence= 2\&isAllowed=y. Acesso em: 25 mar. 2019.

COSTA, F. S. O Prouni e seus egressos: uma articulação entre educação, trabalho e juventude. Interfaces da Educ., Paranaíba, v. 5, n. 14, p. 144-156, 2014. Disponível em: http://periodicosonline.uems.br/index.php/interfaces/article/view/474/440. Acesso em: 25 mar. 2019.

MONTGOMERY, D. C.; RUNGER, G. C. Estatística Aplicada e Probabilidade para Engenheiros. 6. ed. Rio de Janeiro: LTC, 2018. 
PEREIRA, M. S. et al. A relação entre as condições de trabalho e saúde dos estudantes trabalhadores. Revista Saúde e Pesquisa, v. 9, n. 3, p. 525-535, set./dez. 2016.

Disponível em:

http://periodicos.unicesumar.edu.br/index.php/saudpesq/article/view/5573/292. Acesso em: 25 mar. 2019.

SIEGEL, S.; CASTELLAN JR., N. J. Estatística não-paramétrica para ciências do comportamento. Métodos de Pesquisa. 2. ed. Porto Alegre: Bookman, 2006, reimpressão 2008.

SOLOMON, M. R. O comportamento do consumidor: comprando, possuindo e sendo. 11. ed. Porto Alegre: Bookman, 2016.

TERRIBILI FILHO, A; BARREIRO, I. M. de F. O ensino superior noturno no Brasil: história, crescimento e políticas públicas no início do século XXI. Revista Iberoamericana de educaciõn, v. 62, n. 3, 2013. Disponível em:

file:///C:/Users/111828/Downloads/5773Terribili.pdf. Acesso em: 25 mar. 2019.

UNGLAUB, E. Diligência de estudantes de graduação de tempo integral e tempo parcial. Tese (Doutorado em Educação) - Faculdade de Educação. Universidade Estadual de Campinas. Campinas, 2003. Disponível em:

http://repositorio.unicamp.br/jspui/handle/REPOSIP/253627. Acesso em: 11 mar. 2019.

\title{
CHARACTERIZATION OF THE WORKING STUDENT OF NIGHTTIME ENGINEERING COURSES AT A CONFESSIONAL UNIVERSITY
}

\begin{abstract}
The economic crisis that the country is since the last decade has caused many students to enter higher education at night to be able to work during the day and contribute to family income, which often makes the academic life of the student be partially compromised because of this double journey. However, the need to help at home is not the only reason for students to enter the job market early. The objective of this research was to identify the profile of the working student of a night engineering course. The research was made with three questionnaires applied to each of the groups: student who has never worked during the course, student who has worked during the course, but no longer works and student who works now, with the intention of identifying the differences between the worker student and the others. The sample consisted of 208 students enrolled in the engineering course at night at a confessional university, in 2020. Descriptive and inferential analyses were performed. Among the conclusions, it is noteworthy that working night-time students are working longer hours than determined by law and slightly more than half continued to have college as their main objective after entering the job market. Worsening in physical health, mental health, quality of alimentation and sleep was identified after the student started working.
\end{abstract}

Keywords: College students. Working student. Night shift. 